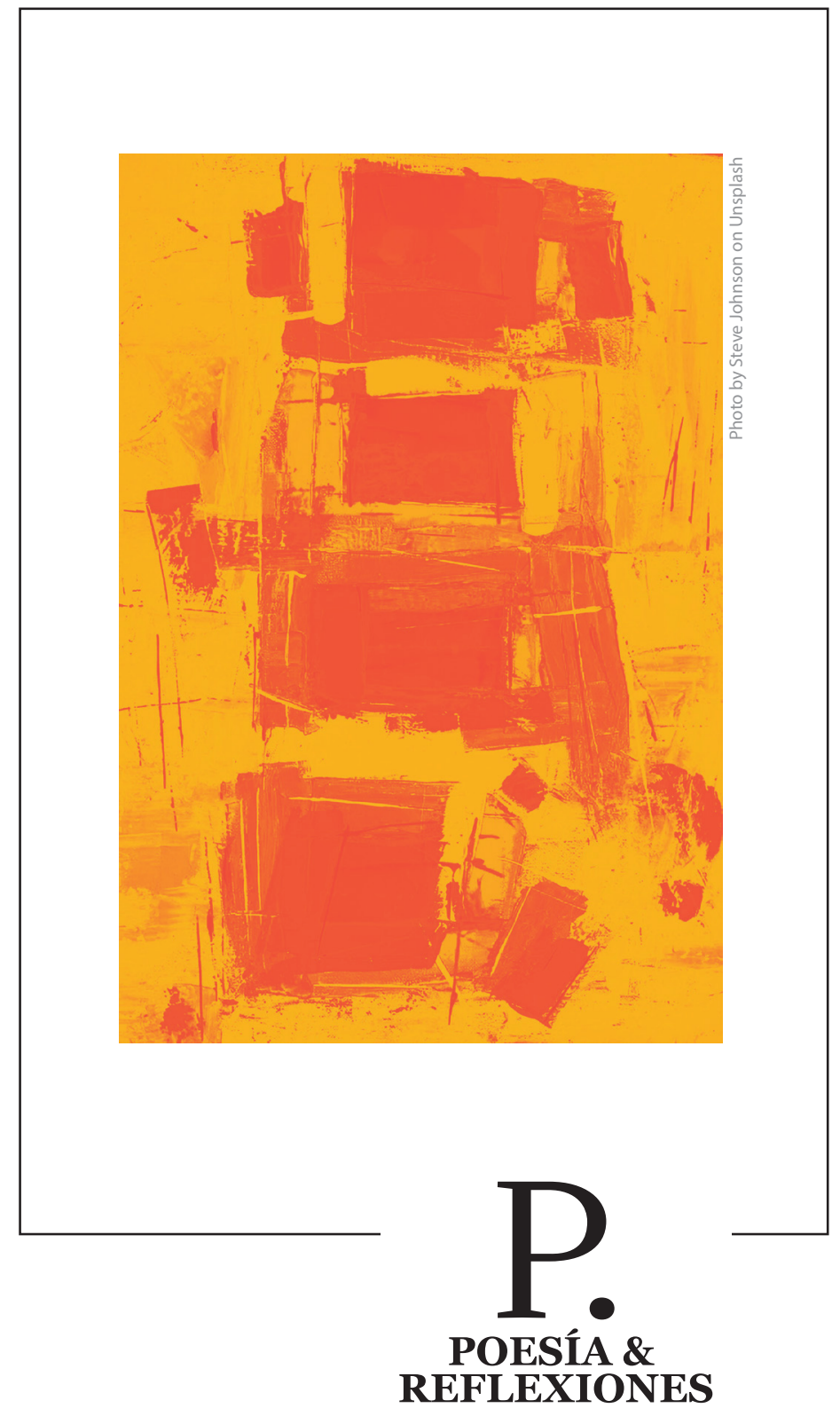




\title{
Ofelia y Fernando, una tragicomedia
}

\author{
Carlos López Degregori
}

Me observa desde una fotografía en blanco y negro protegida por un cristal. La mirada es vivaz, con un ligero brillo irónico. Los labios finos ensayan una sonrisa contenida y equívoca. Lleva en el cuello una delgada cadena que no revela el pendiente y un vestido de tela calada con el escote pronunciado. Una reja de pequeñas lanzas rodea la imagen que cubre casi toda la lápida. Es la tumba de una mujer que falleció en 1991, a la edad de 91 años. La familia, por esas decisiones afectivas que buscan conjurar el tiempo, eligió esa representación juvenil. Quiero pensar que la muchacha de la lápida tiene 19 años y está ante la puerta de la empresa comercial Felix, Valladas e Freitas, que necesita una secretaria. Ha leído el aviso en el diario y es a Fernando Pessoa a quien se le ha encomendado elegir la persona adecuada. La puerta se abre y entra a la oficina. Pasados unos momentos alguien se acerca. Es un encuentro antirromántico y tiene esa plasticidad jocosa de las películas mudas o los teatros de marionetas. Trazos gruesos acentuados por la figura del personaje. Ofelia Queiroz (2016) brinda su testimonio:

En determinado momento veo subir la escalera a un señor todo vestido de negro (supe más tarde que estaba de luto por su padrastro), con un sombrero de ala vuelta y galoneada, lentes y lazo en el cuello. Al caminar parecía que no pisaba el suelo. Y llevaba -lo que no puede parecer más natural - los pantalones metidos en las polainas. No sé por qué aquello me produjo unas terribles ganas de reír. (p. 336)

Es un primer encuentro pleno de histrionismo y es significativa la descripción de Ofelia: destaca el color negro de la vestimenta, los pantalones metidos en las polainas y el desplazamiento silencioso por el aire sin un piso sólido que lo sostenga. Parece solo el atuendo que envuelve un cuerpo vacío, una presencia fantasmática, aunque amable, que proyecta un aura de extrañeza y quizás ridiculez. “Todas las cartas de amor son ridículas", diría más adelante Álvaro de Campos en uno de sus poemas más conocidos. La insignificancia de este primer encuentro parece ser el umbral de la única historia de amor conocida del poeta portugués y de un intercambio epistolar que se extendería, con un largo paréntesis, diez años.

La nueva secretaria descolocó a Pessoa. Es fácil suponer que buscaba aproximarse a ella y la observaba con insistencia. Sentía celos de las otras personas que se le acercaban. Un día, en el que no había nadie más en la oficina, dejó una pequeña nota sobre el escritorio de Ofelia que decía: “Le pido que se quede". La luz se había cortado y solo 
había una lámpara de petróleo en la habitación. Ella estaba poniéndose el abrigo para marcharse, cuando entró Pessoa en el despacho. Imagino las sombras de los dos personajes, la timidez y la inseguridad que genera la espera. Ofelia narra con precisión este momento decisivo:

Se sentó en mi silla, posó la lámpara que traía y, vuelto hacia mí, empezó de pronto a declararse, como Hamlet se declaró a Ofelia: "Oh, iquerida Ofelia! Mido mal mis versos: no tengo arte para medir mis suspiros; pero te amo extremadamente. ¡Oh! ¡Extremadamente, créeme!”.

Quedé sumamente perturbada, por supuesto, y sin saber qué decir, terminé de ponerme el abrigo y me despedí con apuro. Fernando se levantó, con la lámpara en la mano, para acompañarme hasta la puerta. Pero, de pronto, la dejó sobre el muro divisorio; sorpresivamente, me tomó por la cintura, me abrazó y, sin decir palabra, me besó, me besó, me besó apasionadamente como un loco. (Queiroz, 2016, pp. 336-337)

El inicio de esta historia no podría haber sucedido de otra manera. Pessoa, el escritor invisible que solo se vincula con el mundo a través de voces plurales y heterónimos, es por un momento Hamlet. No es Fernando que cita al personaje de Shakespeare, sino Hamlet que ocupa el cuerpo y la voz del poeta portugués. Esta trama amorosa se inicia así en el ámbito de la despersonalización, en la puesta en escena de un "drama" o quizás una "comedia" en "gente": es la ficción que desdibuja la realidad, aunque este encuentro revela también el reclamo del cuerpo que se eriza.

Sé que la narración de Ofelia es testimonial, pero hay un apunte en sus palabras que adquiere un valor simbólico: dejar la lámpara sobre un muro divisorio. El espacio de la oficina está a oscuras y la única luz reposa sobre un punto de apoyo que escinde. A un lado está la ficcionalización del sujeto amoroso que con las palabras de Shakespeare se torna incorpóreo; al otro, el sujeto amoroso real que desea a Ofelia. Esta será la mecánica que determinará los encuentros y desencuentros de la pareja.

Ofelia quedó desconcertada y trató de eludir a Pessoa un tiempo. Parece que reclamaba una definición desde su lugar de muchacha burguesa: un compromiso explícito y formal. Fue entonces que la joven decidió escribirle al poeta solicitando una explicación. La respuesta llegó el 1 de marzo de 1920. La lectura de esta carta nos muestra a un Fernando Pessoa ambiguo. Hay una dimensión de fragilidad en sus palabras que revela la certeza de que es un amor condenado a la imposibilidad:

¿Por qué no es sincera conmigo? Qué empeño tiene en hacer sufrir a quien no le ha hecho daño, ni a usted ni a nadie; a quien tiene por peso y dolor suficiente la propia vida aislada y triste, y que no precisa que nadie venga a aumentárselos creándole falsas esperanzas, mostrándole afectos fingidos. Con qué interés, incluso si fuera por diversión; con qué provecho incluso si fuera por burla. Admito que todo esto resulta cómico, y que la parte más cómica de todo esto soy yo. (Pessoa, 2010, p. 19) 
Esta primera comunicación y la de la ruptura de la primera serie son las únicas cartas que poseen un tono grave y que desnudan al que escribe. Pessoa reconoce su aislamiento y la dificultad que tiene para establecer vínculos con otros seres que no sean los que alberga en su interior; teme ser engañado, convertirse en objeto de burla. Es significativo, además, que estas dos misivas de la primera etapa sean las únicas en las que aparece el nombre Ofelia -Ophelinha, en este caso-. Pero con Pessoa la sensibilidad y las emociones siempre se escinden y se tornan creación estética: no hay realidad que no sea fingimiento y tampoco hay fingimiento que no sea realidad. He destacado en el fragmento de la carta los términos sinceridad y fingimiento. Pessoa los usa como adjetivos, como atributos de las acciones y sentimientos de Ofelia, pero en un espejo regresan a él. Cabe preguntarse cuánto hay de sinceridad en los sentimientos del poeta y cuánto de fingimiento. La relación se inicia así en una zona de indeterminación: ambos son los personajes de una ficción que se ha iniciado y el poeta es también el demiurgo que mueve los hilos de la trama.

En las misivas restantes - las XX-, Pessoa aleja al objeto amoroso; para ello le expropia el nombre y recurre a un proceso de infantilización. Ofelia se desmaterializa: pierde sus atributos adultos y es trasladada a una infancia sutilmente erotizada. Los vocativos en las cartas son Bebé, Bebé angelito, Bebé malo, Bebé pequeño y travieso, Nininha, entre otros, que son variaciones sobre el dominio infantil. El poeta la acompaña en ese viaje para ser el Nininho de Ofelia. El contenido de las cartas abunda en detalles de una cotidianidad trivial, expresiones cursis, horarios y marcas de tiempo, enfermedades comunes. Las palabras no traslucen una situación apasionada o angustiosa, solo recriminaciones y celos, inmediatamente limados por la ironía:

Quién pudiera tener seguridad de que sientes verdaderas saudades de mí, por lo menos eso sería un consuelo... Pero tú, si cabe, piensas menos en mí que en el muchacho del galanteo y en D. A. F. y en el contable de C. D. \& C. iiiiMala, mala, mala, mala, mala...!!!!

Azotes es lo que tú necesitas.

Adiós; voy a echarme dentro de un cubo cabeza abajo para que mi espíritu descanse. Así es como hacen todos los grandes hombres, al menos cuando tienen: $1 .^{\circ}$ espíritu; $2 .^{\circ}$ cabeza; $3{ }^{\circ}$ cubo donde meter la cabeza. (Pessoa, 2010, p. 48)

Las cartas escenifican una comedia amorosa en la que hay más desencuentros que encuentros y en los que falta una corporalidad. Es un amor casto y lúdico que cumple su destino en la simulación. El ritual se limita al ejercicio de la visión, a transitar por delante de la casa de la amada para ser observado desde una ventana, a dejar constancia del deseo con palabras y pequeños objetos que son sucedáneos del abrazo y el encuentro físico. La irrealidad o, mejor, la indefinición de este amor es indispensable, 
una relación que es y no es al mismo tiempo, como la lámpara en el muro divisorio. Hay una anotación en la carta del 28 de mayo de 1920 que me parece decisiva: "El destino es como una persona y deja de molestarnos si mostramos que no nos importa lo que nos haga. Por eso, tú debes tener la fuerza de pensar solo en esto: quiero a Fernando, nada más" (Pessoa, 2010, p. 64).

El "destino" es una "persona" que no existe. No existe Ofelia para Fernando, ni Fernando para Ofelia. Esta inexistencia es la naturaleza del amor: la construcción de un fantasma, de un espejismo que debe bastarse a sí mismo. Para Pessoa, se inventa al otro para negar una radical soledad, la inmovilidad, el desasosiego; pero, paradójicamente, esta situación de inquietud y carencia es lo único que debe preservarse. El objeto del sujeto amoroso tiene que permanecer así en la lejanía, en el dominio de lo inalcanzable. No es exactamente el amor romántico o platónico, sino la conciencia de que es imposible salir del centro inmóvil que aprisiona al yo.

"Nunca amamos a alguien en concreto. Amamos tan solo la idea que nos formamos de alguien. Es un concepto nuestro - es, en suma, a nosotros mismos- lo que amamos" (Pessoa, 2016, p. 49). Esta afirmación de Bernardo Soares, que aparece en el Libro del desasosiego, es fundamental para entender el imaginario amoroso de Fernando Pessoa. Puede incluso decirse que es Soares - el heterónimo más cercano al poeta- quien fija la esencia y los límites del amor real entre Ofelia y Fernando. Es el censor, la presencia invisible que contempla a la pareja y señala el destino de un amor que jamás podrá concretarse. ¿Amó el Fernando Pessoa contingente a Ofelia? ¿Le horrorizaba la sexualidad? ¿Oscilaba su vida diaria entre el deseo y su represión? Nunca lo sabremos. Solo podemos reconocer que la infantilización de Ofelia en las cartas confirma una necesidad de alejamiento. Eres una niña pequeña, parece decir Pessoa, y no puedo poseerte. Hay que girar en el círculo infinito de la seducción, en el umbral de un encuentro carnal siempre interrumpido. La consecuencia es un elogio de la pureza, la convicción de que el cuerpo soñado tiene más esencia que la banalidad de lo real:

No sueño con poseerte. ¿Para qué? Eso sería traducir a plebeyo mi sueño. Poseer un cuerpo es ser banal. Soñar que se posee un cuerpo es probablemente peor, por muy difícil que parezca; es soñarse banal, horror supremo.

Y ya que queremos ser estériles, seamos también castos, porque nada puede haber más innoble y bajo que, renegando de lo que en la naturaleza se fecunda, guardar vilmente de ella lo que nos agrada de lo que renegamos.

Seamos castos como ermitaños, puros como cuerpos soñados, resignados a ser todo eso, como monjitas tontas... (Pessoa, 2016, p. 346)

Se ama un concepto, una encrucijada abstracta. La pasión se diluye y da lugar a la sola fascinación. Ver desde lejos como "monjitas tontas", ironiza Pessoa/Soares, sin 
cuerpo ni ardor, sin el vértigo erótico que triza la perfección de lo imaginario. Hay un apunte bastante sugerente en el Libro del desasosiego que refuerza esta dinámica: una pareja frente a frente en dos vidrieras y entre ellos la calle de "la humanidad pasando" (Pessoa, 2016, p. 347). No se tocan: les basta pensar. Se sumergen en la contemplación, en el placer que brinda la imaginación. El amor de Pessoa es solipsista, no puede abrirse a la realidad, gira en un circuito interno, en un pozo donde está encadenado el deseo. Es el difícil destino de amarse a sí mismo porque no hay un otro ni un afuera. Solo el tumulto de los seres que el poeta guarda en su interior y que le exigen un destino escritural:

En el amor sexual buscamos un placer propio que nos es dado por intermedio de un cuerpo extraño. En el amor distinto del sexual, buscamos un placer propio que nos es dado por intermedio de una idea nuestra. El onanista es abyecto, pero, en rigurosa verdad, el onanista es la perfecta expresión lógica del sentimiento amoroso. Es el único que no disfraza ni engaña. (Pessoa, 2016, p. 348)

El onanismo de este fragmento no es solo sexual y se abre a connotaciones literarias. Es la emisión del texto como materia amorosa. Las semillas que se expulsan solo son palabras que fructifican en el quehacer literario y que engendran una posteridad que Pessoa siempre imaginó. En la carta de ruptura del 29 de noviembre de 1920, confiesa que "su destino pertenece a otra ley" (Pessoa, 2010, p. 92) y está "subordinado a la obediencia de Maestros que no consienten ni perdonan". ¿A qué Maestros se refiere y cuál es el destino que le han señalado? Ese Maestro es la representación de la literatura que exige un compromiso absoluto, es casi un sacerdocio. En este ámbito no cabe el amor: la literatura es su sucedáneo. Ella es madre, amante, esposa.

Durante nueve años la pareja se alejó y una fotografía del poeta bebiendo en "flagrante delitro", que llegó a las manos de Ofelia, reanudó la correspondenciaํ. Del 11 de septiembre de 1929 al 11 de enero del año siguiente, Pessoa le remitió cartas. El tono de ellas, a pesar de la intensificación lúdica y ficcional, no logra ocultar el desdoblamiento y la desintegración del poeta. La relación deja de ser entre dos personas y deviene en un triángulo cuyo tercer vértice es el heterónimo Álvaro de Campos, quien actúa como un censor sarcástico. Él vislumbra el sinsentido del vínculo amoroso y el drama doloroso que hierve debajo de esa comedia aparente.

Dos misivas del 9 de octubre son elocuentes para percibir el desmoronamiento de Pessoa. La primera de ellas es un monólogo que en su libre asociación articula confesiones amorosas exaltadas, el deseo insatisfecho, la solicitud de un falso perdón y la autopunición:

1 Esta fotografía se ha convertido en una imagen paradigmática de Fernando Pessoa. 
por qué Ophelinha quiere a un maleante y a un desastrado y a un zarrapastroso y a un individuo con narices de cobrador del gas y expresión general de no estar allí, sino en el baño de la casa de al lado, y exactamente, y en fin, y voy a terminar porque estoy loco, y lo he estado siempre, y es de nacimiento, que es como quien dice desde que nací, y me gustaría que Bebé fuera una muñeca mía, y yo hacía lo que un niño, la desnudaba y el papel termina aquí mismo y esto parece imposible que lo haya escrito un ente humano, pero está escrito por mí. (Pessoa, 2010, p. 114)

El perfil frágil e irrisorio que proyecta el escribiente de la carta se une a la acción de develar. Mostrarse simultáneamente con subterfugios o sin ellos; ensayar la burla extrema y la confesión en el "papel" que se termina. El término admite en su ambigüedad un doble sentido. Es tanto la lámina de fibras vegetales para escribir como el rol que se cumple en una historia o pieza teatral. Pessoa parece decir que las cartas que sostienen la relación están llegando a un punto de no retorno y también que el rol de sujeto enamorado en esta tragicomedia extendida a lo largo de 10 años ya se ha desvanecido. El impulso confesional se prolonga en la segunda carta del mismo día en la que, tras pedir perdón, confiesa que se "ha roto la correa del automóvil viejo que llevo en la cabeza, y mi juicio que ya no existía, he hecho tr-tr-tr-r-r..." (Pessoa, 2010, p. 115).

Esta carta es clausura y enjuiciamiento de toda la correspondencia. Hay un párrafo en ella que me parece decisivo:

Todas estas frases, y maneras de no decir nada, son señales de que el ex-Ibis, el extinto Ibis, el Ibis sin concierto ni querimiento ajeno, acaba en Telhal o en Rilhafoles, y se le hace una gran manifestación a su magnífica ausencia. (Pessoa, 2010, p. 115)

Una de las transformaciones de Pessoa ha sido la de un ibis, el ave emblemática del antiguo Egipto. El poeta se desprende de ese plumaje, que es la última de sus máscaras. Telhal y Rilhafoles, dos centros para enfermos mentales, que surgen como una amenaza. A partir de esta misiva solo se vislumbra un espacio vacío, casi un traje sin cuerpo y sin lenguaje que pueda prolongar el vínculo. Después de las comunicaciones del 9 de octubre, solo existen dos cartas. La primera de tono afable y distinto, en la que se refiere a una fotografía que enviará. La última es un discurso nonsense, un balbuceo que sigue el ritmo de los números o las horas o los días y que se detiene al fin en el ruido blanco. El lenguaje y las cartas se han desvanecido, y solo queda la imagen fija de Ofelia muy parecida, imagino, a la fotografía de su lápida.

La realidad prolongó esta comedia. En 1935, se unió en matrimonio con el teatrólogo Augusto Soares. Es como si hubiera contraído nupcias con una persona que restituía el nombre de quien observó su relación con Fernando Pessoa. Entonces aún no se conocía la existencia del Libro del desasosiego. El poeta continuó su deambular por las calles de la Baixa, bebía cada vez más en "flagrante delitro" y escribía casi sin detenerse encadenado a su grafomanía. Álvaro de Campos dice en el poema "Tabaquería" que si se hubiera 
casado con su lavandera, tal vez hubiera sido feliz. Pessoa solo se unió en nupcias con sus heterónimos, con los grandes maestros que señalaban su destino literario. Estoy seguro de que no fue feliz ni infeliz. Ofelia vivió hasta los noventa años sin una mirada vivaz, ni un brillo irónico en los ojos.

\section{REFERENCIAS}

Pessoa, F. (2010). Cartas a Ofelia. Barcelona: Libros del Zorro Rojo.

Pessoa, F. (2016). Libro del desasosiego. Madrid: Acantilado.

Queiroz, O. (2016). Fernando y yo. En F. Pessoa, Papeles personales (pp. 334-344). Santiago de Chile: Ediciones Universidad Diego Portales.. 